\title{
CORRELATION OF SERUM LOW DENSITY LIPOPROTEIN CHOLESTEROL AND HIGH DENSITY LIPOPROTEIN CHOLESTEROL WITH TYPE 2 DIABETES MELLITUS
}

\author{
YEASMIN N ${ }^{1}$, AKTHER QS ${ }^{2}$, MAHMUDA S $^{3}$, YEASMIN S ${ }^{4}$, AFROZ R ${ }^{5}$, HASAN ${ }^{6}$, RABBANI R ${ }^{7}$,
} AKHTER $\mathrm{S}^{8}$, CHOWDHURY MAM ${ }^{9}$, DHAR $\mathrm{U}^{10}$

\begin{abstract}
Background: Diabetes mellitus is one of the most widespread endocrine disorders in female and its complications are increasing all over the world, leading to life threatening medical problems like cardiovascular diseases, stroke and end stage renal diseases. A correlation between hyperlipidemia and type 2 diabetes mellitus has been identified. The study was carried out to observe the correlation of serum low density lipoprotein cholesterol (LDL-C) and high density lipoprotein cholesterol (HDL-C) level with type 2 diabetes mellitus in adult female subjects.
\end{abstract}

Method: This cross sectional study was conducted in the Department of Physiology, Dhaka Medical College, Dhaka, during the period of January 2011 to December 2011. Total sixty female subjects were selected with age ranging from 30 to 50 years. Among them 30 female subjects with diabetes mellitus were included from out-patient department of Endocrinology, Dhaka Medical College Hospital, Dhaka as study group (B) and 30 apparently healthy females were taken as control group (A) for comparison. Estimation of serum fasting serum LDL-C and HDL-C levels was done by enzymatic method in the department of Physiology, Dhaka Medical College Dhaka in both groups. Fasting serum insulin level was measured by ELISA method in the laboratory of National Institute of ENT, Dhaka and fasting blood glucose was estimated by glucose oxidase method in the department of Physiology, Dhaka Medical College in both groups. Data were analyzed by Unpaired Student's- test and Pearson's correlation co-efficient (r) test as applicable.

Results: The value of fasting serum $L D L-C$ level was significantly higher in study subjects than those of control. Again, fasting serum HDL-C level was significantly lower in study subjects in comparison to controls. In study subjects fasting serum $L D L$ showed positive correlation and fasting serum HDL-C levels showed negative correlation with fasting blood glucose and serum insulin level.

Conclusion: Present study reveals that serum insulin and blood glucose level have positive relationship with low density lipoprotein cholesterol $(L D L-C)$ and negative relationship with high density lipoprotein cholesterol (HDL-C) levels.

Key words: Fasting serum insulin, blood glucose, serum low density lipoprotein, serum high density lipoprotein, diabetes mellitus.

J Dhaka Med Coll. 2017; 26(2) : 140-147

1. Dr. Nahid Yeasmin, Assistant Professor, Department of Physiology, Dhaka Medical College, Dhaka.

2. Dr. Qazi Shamima Akhter, Professor \& Head, Department of Physiology, Dhaka Medical College, Dhaka.

3. Dr. Sayeeda Mahmuda, Associate Professor, Department of Pathology, National Institute of Ophthalmology \& Hospital, Sher-E-Bangla Nagar, Dhaka.

4. Dr. Sultana Yeasmin, Assistant Professor, Department of Pharmacology, Dhaka Medical College, Dhaka.

5. Dr. Rumana Afroz, Assistant Professor, Department of Pharmacology, Dhaka Medical College, Dhaka.

6. Dr. Mahmudul Hasan, Junior consultant, Department of Medicine, Dhaka Medical College Hospital, Dhaka.

7. Dr. Rukhshana Rabbani, Assistant Professor, Department of Radiotherapy, Dhaka Medical College, Dhaka.

8. Dr. Shamima Akhter, Assistant Professor, Department of Physiology, Dhaka Medical College, Dhaka.

9. Dr. Md. Ashif Mashud Chowdhury, Associate Professor, Department of Medicine, Dhaka National Medical College, Dhaka 10. Dr. Uma Dhar, OSD, DGHS, Dhaka

Correspondence : Dr. Nahid Yeasmin, Assistant Professor, Department of Physiology, Dhaka Medical College, Dhaka, Mobile: 01923619159, e-mail: masudaatiqua237@gmail.com

Received: 10 January $2017 \quad$ Revision: 11 June 2017

DOI: http://dx.doi.org/10.3329/jdmc.v26i2.38832

Accepted: 01 September 2017 


\section{Introduction}

Diabetes mellitus (DM) is a group of metabolic diseases characterized by hyperglycemia resulting from defect in insulin secretion, insulin action or both ${ }^{1}$. Diabetes mellitus (DM) is one of the common non-communicable diseases and it is one of the most challenging health problems in the $21^{\text {st }}$ century. ${ }^{2}$ There are two general types of diabetes mellitus, one is type 1 or insulin dependent DM (IDDM) and other is type 2 or non-insulin dependent DM. Among them, type 2 diabetes mellitus is more common and about 90 to $95 \%$ of all cases of diabetes mellitus. ${ }^{3}$

Type 2diabetes mellitus the most prevalent form of disease, is often asymptomatic in the early stages and can remain undiagnosed for many years. Type 2 diabetes mellitus and its prevalence has increased continuously over past decades. Rapid economic growth, increased life expectancy and altered life style have significantly increased the prevalence of type 2 diabetes mellitus in adult female. ${ }^{4}$ The chronic hyperglycemia of diabetes mellitus is associated with long term dysfunction, damage and failure of various organs especially the eyes, kidney, nerves, heart and blood vessels ${ }^{5}$.

According to American Diabetes Association, diagnostic criteria of diabetes mellitus are fasting blood glucose e" $7.0 \mathrm{mmol} / 1$ or 2 hours after $75 \mathrm{gm}$ glucose e" $11.1 \mathrm{mmol} / 1$ or random blood glucose e" $11.1 \mathrm{mmol} / 1$ or HbA1c e" $6.5 \%$. ${ }^{6}$.

According to International Diabetic Federation (IDF), about 24.4 million diabetic people in USA, 65.1 million in India and 5.1 million in Bangladesh. This number is gradually increasing day by day will rise to 592 million by the year 2035 representing about $8.8 \%$ of the world population. By the year 2035, the number of diabetic people will be about 29.7 million in USA, 109.2 million in India and 16.8 million in Bangladesh. In each year about 5\% of all deaths are caused by diabetes mellitus globally ${ }^{7}$.

Hyperlipidemia is the most important risk factor for premature cerebrovascular diseases, stroke and peripheral vascular diseases ${ }^{8}$. It is a medical condition characterized by an elevation of any or all lipids and lipoproteins in the blood.
Alteration or abnormality in the metabolism of lipid and lipoprotein is very common condition that taken place within general population. Hyperlipidemia accounts for an estimated 54\% of all strokes and $50 \%$ of all ischemic heart diseases.9. A study in the USA found approximately one in every six adult has hyperlipidemia or high cholesterol in their blood. People with high cholesterol have twice the risk for heart diseases than people with lower level of cholesterol but they are unaware of this condition because there are no symptoms ${ }^{10}$.

Cholesterol is a major structural component of cell membrane and is especially abundant in nerve and brain tissue. It is also a precursor of vitamin $\mathrm{D}$ and hormones ${ }^{11}$. According to National Cholesterol Education Programmed Adult Treatment Panel III (NCEP-III) guidelines was referred hypercholesterolemia is defined as total cholesterol as $\mathrm{TC}>200 \mathrm{mg} / \mathrm{dl}$, low density lipoprotein as LDL-C $>100 \mathrm{mg} / \mathrm{dl}$, hypertriglyceridemia as $\mathrm{TG}>150 \mathrm{mg} / \mathrm{dl}$ and high density lipoprotein as HDL-C $>46 \mathrm{mg} / \mathrm{dl}$. Among them low density lipoprotein cholesterol (LDL-C) and high density lipoprotein cholesterol (HDL-C) are the most important cholesterols that carry lipid to and from cells ${ }^{12}$.

LDL-C is called "bad" cholesterol, because it contributes to build up fatty plaque in arteries and raise the risk for heart attack, stroke and peripheral artery diseases. Again HDL-C is called "good" cholesterol because it acts as a scavenger, carries lipid away from the arteries and back to the liver. There it is broken down and passed from the body. Increased HDL-C protects against heart attack and stroke. ${ }^{13} \mathrm{~A}$ study by Packard et al. reported that reduced HDL-C is a powerful predictor for premature coronary heart diseases. A number of functions of HDL particles may contribute to direct cardioprotective effect, including promotion of cellular cholesterol efflux and direct antioxidative and anti-inflammatory properties ${ }^{14}$. Moreover, low HDL-C levels are accompanied by elevated triglycerides level and the combination have been strongly associated with an increased risk of coronary heart disease ${ }^{15}$. 
Hyperlipidemia is very common in type 2 diabetes mellitus. Many factors account for increased cardiovascular risk in diabetes mellitus but lipid abnormalities are major contributors. The common abnormalities are in diabetes mellitus is elevated triglycerides, total cholesterol and increased presence of small dense LDL-C and low level of HDL-C ${ }^{16}$. Prevalence of hyperlipidemia in type $2 \mathrm{DM}$ is $62-75 \%$. The risk of cardiovascular diseases and cardiovascular mortality is significantly increased in patient with type 2 diabetes mellitus compared to healthy individual ${ }^{17}$. Lipid abnormalities observed in type $2 \mathrm{DM}$ are not only quantitative, but also qualitative and kinetic in nature. A number of factors may contribute to the change in lipid metabolism in type $2 \mathrm{DM}$, including insulin resistance and/or relative insulin deficiency, adipocytokines (Adiponectin) and hyperglycemia ${ }^{18,19}$.

Insulin resistance represents the earliest detectable abnormality in of type 2 diabetes mellitus and is one of the major underlying mechanisms that increases LDL-C and cardiovascular diseases and also decreases HDL-C levels ${ }^{20}$. Insulin is the most potent anabolic hormone which is secreted by beta cells of pancreatic islets of Langerhans in response to increased circulating level of glucose and amino acid after a meal. Insulin has important role in lipoprotein metabolism and the effects of insulin on lipoprotein metabolism are: insulin inhibits hormone-sensitive lipase, hepatic triglyceride rich very low density lipoprotein production, and activates lipoprotein lipase and increases LDL receptor protein expression on the plasma membrane ${ }^{21}$.

In type 2 diabetes mellitus many factors may affect blood lipids level, because of interrelationship between carbohydrate and lipid metabolism. Therefore, any disorder in carbohydrate metabolism leads to disorder in lipid metabolism and vice versa 22 .

A number of studies have shown the relationship between LDL-C, HDL-C and insulin resistance in type- 2 diabetes mellitus and they suggested that insulin resistance or insulin deficiency affects key enzymes and pathways in lipid metabolism. In particular, the following processes are affected: Apo protein production, regulation of lipoprotein lipase, action of cholesteryl ester transfer protein and hepatic and peripheral actions of insulin. ${ }^{4-7,23}$

Again some researchers suggested that adiponectin (a hormone secreted from adipose tissue) is associated with insulin resistance and plays an important role in development of increased level of LDL-C and decreased level HDL-C in type 2 diabetes mellitus. Lower level of adiponectin is positively associated with LDL$\mathrm{C}$ and negatively associated with HDL-C level ${ }^{24}$.

A study was done in Western Europe and they found that at least one-third of the population with type 2 diabetes mellitus has hyperlipidemia and patients with hyperlipidemia also show evidence of diabetes mellitus. Thus type 2 diabetes mellitus and hyperlipidemia are common intertwined conditions that share a significant overlapping risk factors and complications $^{25}$.

Some studies have been done on this regard in abroad but no published data has yet been available on this aspect in our country. Therefore, the present study has been designed to observe the correlation of serum LDL-C and HDL-C levels with type 2 diabetes mellitus in adult females. Better understanding of these metabolic changes with hyperlipidemia will help in the detection of women at risk for future cardiovascular diseases and renal diseases. Treatment and preventive measure can reduce the risk of developing cardiovascular diseases and thus reduce burden on our health budget

\section{Methods}

This cross sectional study was conducted in the department of Physiology, Dhaka Medical College, Dhaka, during the period of January 2011 to December 2011. Thirty females of 3050 years age range with type 2 diabetes mellitus were included in this study as study (B) group. They were selected from the out-patient department of Medicine of Dhaka Medical College Hospital, Dhaka. Age matched thirty apparently healthy females were taken as control (A) group for comparison. Subjects having history of heart, liver, kidney diseases, endocrine disorders and women taking hormone 
replacement therapy, steroid, alcohol user, and smoker were excluded from the study. After selection of subjects, the objectives, nature, purpose and benefit of the study were explained to the subjects in detail. Written informed consent was taken from the participants. They were encouraged for voluntary participation. They were also allowed to withdraw themselves from the study whenever they feel like. Ethical permission was taken from ethical committee of Dhaka Medical College. Detailed medical history, menstrual history and family history of the subjects were taken and recorded in a pre-designed data collection form. The subjects were advised to attend the laboratory in the department of Physiology of Dhaka Medical College, Dhaka between 8AM to 10AM in fasting state. Then with all aseptic precautions $5 \mathrm{ml}$ of venous blood was drawn from antecubital vein by disposable plastic syringe. Blood was allowed to clot and then centrifuged at rate of $3000 \mathrm{rpm}$ and supernatant clear serum was separated. Serum was taken in eppendrof tube and was preserved in refrigerator. Fasting serum insulin level was assessed by Enzyme Linked Immunosorbent Assay (ELISA) method in the laboratory of National Institute of ENT, Dhaka and fasting blood glucose level was estimated by glucose oxidase method in the laboratory of department of Physiology of Dhaka Medical College, Dhaka. Fasting serum LDL-C and fasting HDL-C level was estimated by enzymatic method in the laboratory of Department of Physiology of Dhaka Medical College, Dhaka. Statistical analysis was done by Unpaired Student's t- test. Correlation was analyzed by Pearson's correlation co-efficient ( $r$ ) test. P value $<0.05$ was taken as of significance.

\section{Results}

In this study, the mean ( \pm SD) of low density lipoprotein was $77.53 \pm 16.72 \mathrm{mg} / \mathrm{dl}$ in group A and $134.20 \pm 27.48 \mathrm{mg} / \mathrm{dl}$ in group B. The level of serum low density lipoprotein was significantly higher in group B than that of control and the result was statistically significant $(\mathrm{p}<0.001)$.

The mean $( \pm \mathrm{SD})$ of serum high density lipoprotein was $58.27 \pm 10.09 \mathrm{mg} / \mathrm{dl}$ in group A and $42.60 \pm 7.84 \mathrm{mg} / \mathrm{dl}$ in group B. The level of high density lipoprotein was significantly lower in group B than that of controls and the result was statistically significant $(p<0.001)$ (Table-I).

\section{Table I}

Fasting serum low density lipoprotein (LDL-C) and serum high density lipoprotein $(H D L-C)$ in both groups

\begin{tabular}{lccc}
\hline Groups & $\mathrm{n}$ & $\begin{array}{c}\text { LDL-C (mg/dl) } \\
(\mathrm{Mean} \pm \mathrm{SD})\end{array}$ & $\begin{array}{c}\text { HDL-C }(\mathrm{mg} / \mathrm{dl}) \\
(\mathrm{Mean} \pm \mathrm{SD})\end{array}$ \\
\hline $\mathrm{A}$ & 30 & $77.53 \pm .16 .72$ & $58.27 \pm .10 .09$ \\
$\mathrm{~B}$ & 30 & $134.20 \pm .27 .48$ & $42.60 . \pm 7.84$ \\
\hline
\end{tabular}

Statistical analysis

\begin{tabular}{lcc}
\hline Groups & $\begin{array}{c}\text { LDL-C } \\
\text { (p value) }\end{array}$ & $\begin{array}{c}\text { HDL-C } \\
\text { (p value) }\end{array}$ \\
\hline A vs B & $0.001^{* * *}$ & $0.001^{* *}$ \\
\hline
\end{tabular}

Unpaired Student's ' $t$ ' test was performed to compare between groups. The test of significance was calculated and $\mathrm{p}$ values $<0.05$ was accepted as level of significance.

Group A : Healthy adult female

Group B : subjects with hyperlipidemia

$* / * * / * * *=$ Significant

The mean $( \pm \mathrm{SD})$ of fasting serum insulin level was $5.76 \pm 3.27 \mathrm{uIU} / \mathrm{ml}$ in group $\mathrm{A}$ and $20.58 \pm 6.57 \mathrm{uIU} / \mathrm{ml}$ in group B. The level of serum insulin was significantly higher in group $B$ than that of control and the result was statistically significant $(p<0.001)$. The mean $( \pm \mathrm{SD})$ of fasting blood glucose level was $5.08 \pm 1.25 \mathrm{mmol} / \mathrm{L}$ in group A and 9.91. \pm 3.32 $\mathrm{mmol} / \mathrm{L}$ in group B. The level of blood glucose was significantly higher in group B than that of control and the result was statistically significant $(p<0.001)$ (Table-II).

Serum fasting LDL-C level showed positive correlation ( $\mathrm{r}=0.825)$ with fasting serum insulin level in study group and result was statistically significant $(\mathrm{p}<0.001)$. Serum LDL-C level showed positive correlation $(\mathrm{r}=0.970)$ with fasting blood glucose level in study group and result was also statistically significant $(\mathrm{p}<0.001)$ (Table-III and Figure-1, 2).

Again, fasting serum HDL-C level showed negative correlation $(r=-0.612)$ with fasting serum insulin level and also showed negative correlation ( $r=-0.650)$ with fasting blood glucose in study group and result was statistically significant $(p<0.001)$ (Table-IV and Figure 3,4). 
Correlation of Serum Low Density Lipoprotein Cholesterol and High Density Lipoprotein Cholesterol Yeasmin N et al

\section{Table II}

Fasting serum insulin (FSI) and Fasting blood glucose (FBG) levels in both groups

\begin{tabular}{|c|c|c|c|}
\hline Groups & $\mathrm{n}$ & $\begin{array}{c}\text { FSI (uIU/ml) } \\
(\text { Mean } \pm \text { SD) }\end{array}$ & $\begin{array}{c}\text { FBG }(\mathrm{mmol} / \mathrm{L}) \\
(\mathrm{Mean} \pm \mathrm{SD})\end{array}$ \\
\hline $\bar{A}$ & 30 & $5.76 . \pm 3.27$ & $5.08 \pm .1 .25$ \\
\hline B & 30 & $20.58 \pm 6.57$ & $9.91 \pm .3 .32$ \\
\hline
\end{tabular}

Statistical analysis

Groups FSI ( $\mathrm{p}$ value)FBG ( $\mathrm{p}$ value)

A vs $B \quad 0.001^{* * *} \quad 0.001^{* * *}$

Unpaired Student's't' test was performed to compare between groups. The test of significance was calculated and $p$ values $<0.05$ was accepted as level of significance.

Group A : Healthy adult female

Group B : Diabetic adult female

$\mathrm{n}=$ Number of subjects

ns $\quad=$ Not significant

$* / * * * * *=$ Significant

Table-III

Correlation of fasting serum low density lipoprotein level with FSI and FBG in study group (B)

\begin{tabular}{lcc}
\hline Parameters & \multicolumn{2}{c}{ Group B $(\mathrm{n}=30)$} \\
& $\mathrm{r}$ & $\mathrm{p}$ \\
\hline Fasting serum insulin (FSI) & +0.825 & 0.001 \\
Fasting blood glucose (FBG) & +0.970 & 0.001 \\
\hline
\end{tabular}

Pearson's correlation coefficient $(\mathrm{r})$ test was performed to compare relationship between parameters. The test of significance was calculated and $\mathrm{p}$ value $<0.05$ was accepted as level of significance.

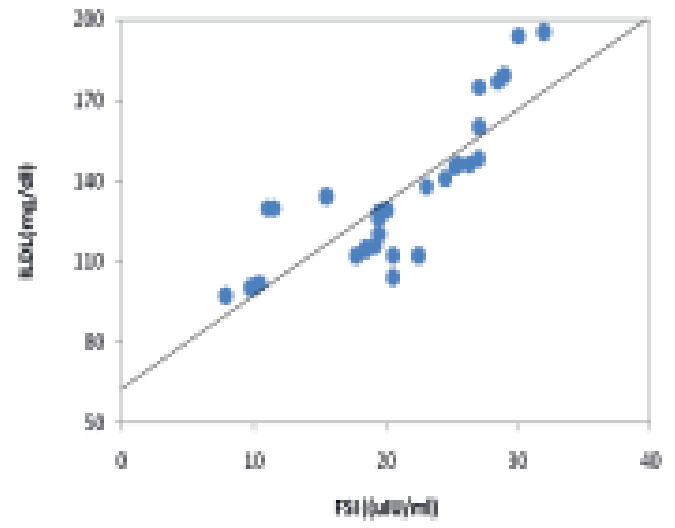

Figg.-1: Correlation of Serum LDL with FSI in study group $(n=30)$

$\mathrm{n}=$ number of subjects in study group; $\mathrm{r}=0.825$; $\mathrm{p}=<0.001$

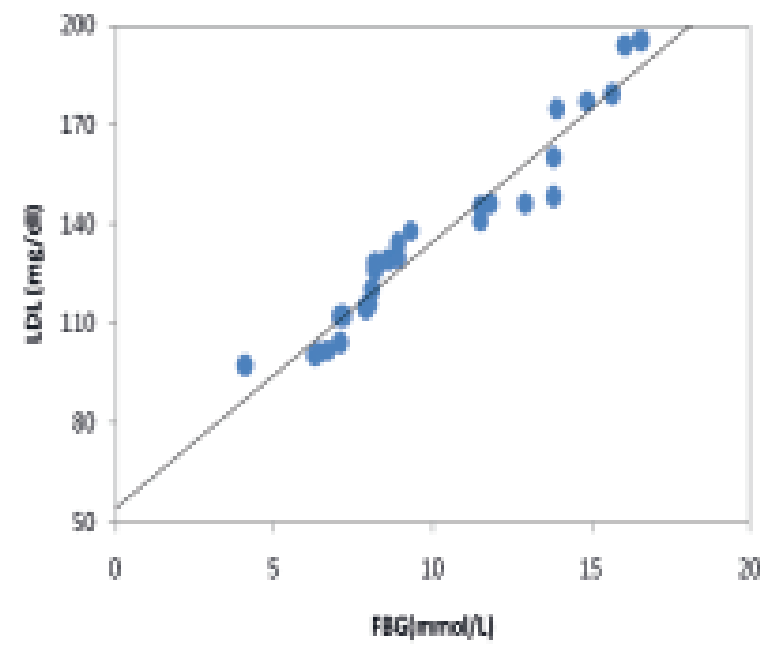

Fig.-2: Correlation of Serum LDL with FBG in study group $(n=30)$

$\mathrm{n}=$ number of subjects in study group; $\mathrm{r}=0.970$; $\mathrm{p}=<0.001$

Table IV

Correlation of serum high density lipoprotein level with FSI and FBG in study group

\begin{tabular}{lcc}
\hline Parameters & Group B $(\mathrm{n}=30)$ \\
& $\mathrm{r}$ & $\mathrm{p}$ \\
\hline Fasting serum insulin & -0.612 & 0.001 \\
Fasting blood glucose & -0.650 & 0.001 \\
\hline
\end{tabular}

Pearson's correlation coefficient $(r)$ test was performed to compare relationship between parameters. The test of significance was calculated and $p$ value $<0.05$ was accepted as level of Significance.

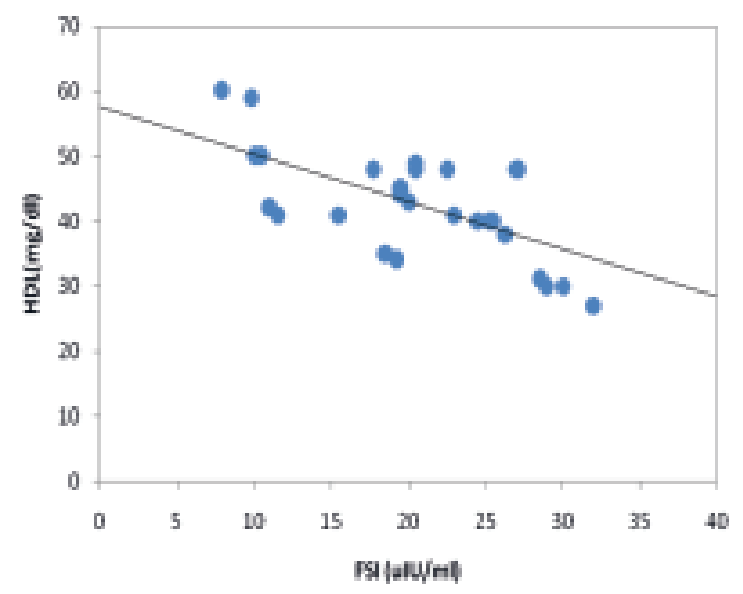

Fig.-3: Correlation of Serum HDL with FSI in study group $(n=30)$

$\mathrm{n}=$ number of subjects in study group; $\mathrm{r}=$ $0.612 ; \mathrm{p}=<0.001$ 


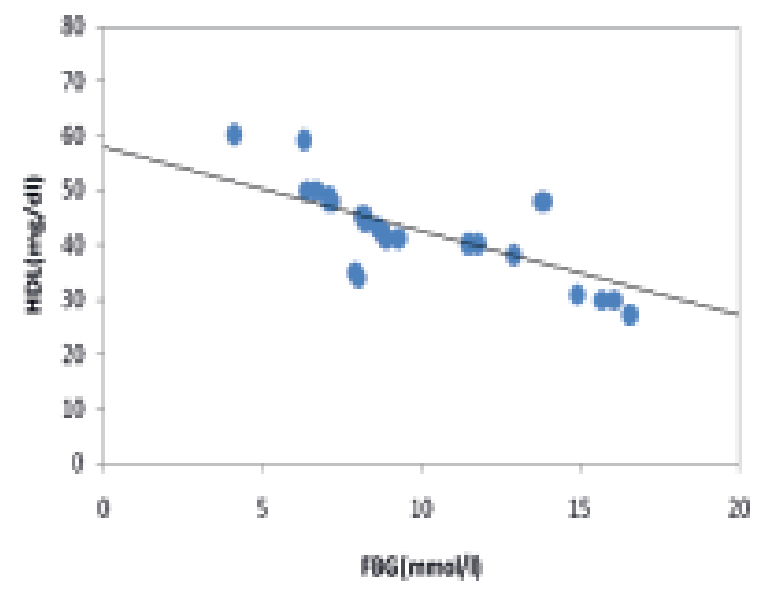

Fig.-4: Correlation of serum HDL with FBG in study group $(n=30)$

$\mathrm{n}=$ number of subjects in study group; $\mathrm{r}=$ $0.650 ; p=<0.001$

\section{Discussion}

In the present study, the values of fasting low density lipoprotein (LDL-C) and high density lipoprotein ( HDL-C) in controls were almost within normal range and also similar to reported by the several investigators from abroad ${ }^{5-11}$.

In this study, the level of LDL-C in the study group was higher than that of control and the result was statistically significant. Similar types of observation were found by other workers ${ }^{5-9}$. The level of HDL-C in study subjects was lower than that of control and the result was statistically significant. Similar types of findings were reported by different researchers of different countries. ${ }^{5-7,10}$ On the contrary, similar observation was made by other researchers but they did not find any significant difference in LDL-C level between the groups. It may be due to nutritional and environmental variation and life style difference in their study population $^{12}$.

Again, correlation analysis showed positive correlation of serum LDL-C level with fasting serum insulin and fasting blood glucose level. However, serum HDL-C level showed negative correlation with fasting serum insulin and fasting blood glucose level. The results were statistically significant. Similar observation was also reported by some investigators. ${ }^{16}$

The exact possible mechanism regarding these observed effects cannot be revealed directly from present study. However, several investigators of different countries proposed various suggestions on these aspects, which might be the cause of our present findings. It has been suggested that in the present study serum LDL$\mathrm{C}$ are higher and serum HDL-C level are lower in study group than those of control. Lipid metabolism in type 2 diabetes mellitus is modulated by series of factors among which insulin resistance is the most prominent feature. Insulin resistance is the pathophysiologic mechanism of diabetic hyperlipidemia. ${ }^{24}$ Insulin resistance in adipose tissue causes increased activity of hormone sensitive lipase resulting in increased level of circulating fatty acids. These fatty acids are carried to the liver where they converted to very low density lipoprotein (VLDL-C), resulting in elevated serum LDL-C level. ${ }^{25}$ Again, due to insulin resistance in type 2 diabetes mellitus lipoprotein lipase (LPL) activity is decreased. Therefore, decreased activity of LPL also decreases the catabolism of LDL-C. Moreover, in patients with insulin resistance, both the number of LDL receptors and receptor mediated endocytosis of LDL decrease. ${ }^{26}$ Again, Insulin resistance is an important factor that increases the number of small dense LDL particles. These small dense LDL particles are not catabolized by LDL receptors. Thus LDL level is increased in blood ${ }^{27}$ Besides, in type $2 \mathrm{DM}$ excess free radicals cause oxidation of lipid. Low density lipoprotein is highly susceptible to oxidation. This oxidized LDL cannot be recognized by LDL receptor in liver for catabolism. As a result, the level of LDL-C is increased in blood. Many researchers suggested that in type $2 \mathrm{DM}$, defect in insulin action leads to inactivation of lipoprotein lipase. This in turn causes inhibition of lipolysis of very low density lipoproteins (VLDL-C). So, surface remnants such as apoprotein-phospholipid free cholesterol complex cannot be transferred from VLDL-C to synthesize HDL-C. Again, inactivation of lipoprotein lipase causes inhibition of lipolysis of VLDL-C leading to reduced HDL-C production. This may result in decreased production of HDL-C in blood. ${ }^{27,28}$

Moreover, increased cholesterylester transfer protein activity due to insulin resistance 
increases the transfer of triacylglycerol from triglyceride rich lipoprotein VLDL-C to LDL-C and HDL-C. These triacylglycerol rich HDL-C are more susceptible to catabolism by hepatic lipase $^{29}$

ApoB100 containing lipoproteins are VLDL-C and LDL-C. Several studies found an inverse association between Apo-B100 and serum level of adiponectin. So, decreased level of adiponectin in insulin resistance is associated with increased level VLDL-C and LDL-C. Again, decreased adiponectin also decreases the catabolism of LDL-C and increases the synthesis of LDL-C. Furthermore, insulin resistance is associated with some inflammatory cytokines namely leptin, tumour necrosis factor (TNF- \pm ), transforming growth factor- ${ }^{2}\left(\mathrm{TGF}^{2}\right)$, IL-6. These inflammatory cytokines decrease the expression of LDL receptor and decrease LDL uptake from circulation and thereby increase serum LDL level in circulation. ${ }^{30}$

ApoA-I and ApoA-II are the major apolipoprotein constituents of HDL-C and Apo-B100 is the major protein constituent of all lipoproteins (VLVL, IDL and LDL). TNF- \pm and IL-6 decrease the production of apolipoprotein ApoA-I and increases the synthesis of apolipoprotein B100. So,Apo-B100 containing LDL-C synthesis increases and ApoA-1 containing HDL-C level decreases in type 2 DM. $^{30,31}$

\section{Conclusion}

From this study, it can be concluded that hyperlipidemia present in the study group may be due to insulin resistance and high blood glucose level. Furthermore, in the present study fasting serum LDL-C showed positive correlation with fasting serum insulin and blood glucose level whereas HDL-C level showed negative correlation with fasting serum insulin and blood glucose level. These findings support the relationship between the level of serum LDL$\mathrm{C}$ and HDL-C with elevated fasting insulin and blood glucose level.

\section{Acknowledgement}

The authors are thankful to the study subjects for their active, sincere and voluntary participation. The authors are also grateful to the Department of Physiology, Dhaka Medical
College and the department of Endocrinology, Dhaka Medical College Hospital for their kind support.

\section{References}

1. King H. The rising global burden of diabetes and 1995-2025: prevalue, numerical estimatics and projection. Diabetes Care.2000;21:123-8.

2. Pooja Maharjan, Dipendra Raj Pandey, Govardhan Joshi, Sakrita Hona, Bibek Bhatta, Alneli M. Glycated Hemoglobin(HBA1C) is a predictor of dyslipidemia in type 2diabetes Nepalese patient. International Journal of an advanced research.2017; 5(2):113-8.

3. Hall, JE.Text Book of Medical Physiology. $12^{\text {th }}$ ed. India: Elsvier Inc; 2011.939

4. Ahmed. KA, Muniandy S, Ismail IS. Type 2 diabetes and vascular complication: A pathophysiological view. Biomed Res. 2010; 21 (2): 147-8

5. Amit Kumar Dixit, Ranjit Dey, Aela Suresh, Siddhartha Chaudhuri, Ashok kumar Pande, Achintya Mitra. The prevalence of Dyslipidemia in patients with diabetes mellitus of Ayureveda Hospital. Journal of Diabetes \& Metabolic Disorders.2014; 13(58): $1-6$

6. American Diabetes Association. Classification and Diagnosis of Diabetes. Diabetes care.2015; 38(1):S816.

7. Guariguata .L, Whiting. DR, Hambleton I. Global estimates of diabetes prevalence for 2013 and projections for 2035. Diabetes Res Clin Pract. 2013; 103(2014): 137-49.

8. IDF Diabetes Atlas. $6^{\text {th }}$ ed. Brussels, Belgium: International Diabetes Federation; 2013.

9. Bruno Verges. Pathophysiology of Diabetic dyslipidemia: Where are we? Diabetologia.2015; 58(1):886-13.

10. Mercurio V, Carlomango G, Fazio V \& Fazio S. Insulin resistance is it time for primary prevention? World $\mathrm{J}$ Cardiol.2012; 4(1):1-7.

11. Pessin. JH \& Sal. Signatiel AR. Signaling pathways in insulin action: molecular targets of insulin resistance. J Clin Ivest.2000; 106(2):64-69.

12. Klause G Parhofer. Pathophysiology of diabetic dyslipidemia: Implications for atherogenesis and treatment. Clinical Lipidology.2011; 6(1):401-10.

13. Ronald M. Krauss. Lipids and Lipoproteins in patients with type 2 diabetes. Diabetes Care. 2004; $27(1): 1496-8$.

14. Packrd C, Nuunn A, Hobbs R. High density lipoprotein: Guardian of the vascular system. Inter $\mathrm{J}$ Clin Pract.2002; 56:761-10.

15. Ira j. Goldberg. Diabetic Dyslipidemia: Causes and Consequences. The journal of clinical Endocrinology and Metabolism.2001; 86(3):965-6. 
16. Clay F. Semenkovich. Insulin resistance and atherosclerosis. J Clin. Invest. 2006; 116(1):1813-9.

17. Prashant Regmi, Prajwali gyawali, Rojeet Shresthaa, Manoj Sigdel,Kisun D Mehta, Shanker Majhi. Pattern of dyslipidemia in type 2 diabetic subjects in Eastern Nepal.JNAMLS.2009; 10(1):11-2.

18. H.A. Elnasri and A.M. Ahmed. Pattern of lipid changes among type 2diabetes patients in Sudan.Eastern Mediterranean Health journal, 2008; 14(2):31410.18 .

19. Thapa Subarna Dhoj, KC Shiva Raj, Gautam Santosh, Gyawali deepika. Dyslipidemia in type 2 diabetes mellitus. Journal of pathology of Nepal.2017; 7(1): 1149-5.

20. Ramprasad Gadi, and Frederick F. Samaha. Dyslipidemia in type 2 Diabetes Mellitus. Current Diabetes Reports.2007; 7(1):228-6.

21. Champe,PC, Harhey, RA, Ferrier, DR.Lippincott's illustrated reviews: Biochemistry, $4^{\text {th }}$ ed, 2008; Wolters Kluwers, New Delhi.

22. Rafael Carmena.High Risk of lipoprotein dysfunction in type 2 diabetes mellitus. Rev Esp Cardiol Supl.2008; 8(1): 18c-24c.

23. Scott M Grundi. Hypertriglyceridemia, insulin Resistance, and the metabolic syndrome.Am J Cardiol.1999; 83(1):25F-29F.

24. G. A. Christou and D.N Kiortsis. Adiponectin and lipoprotein metabolism. Etiology and Pathophysiology. 2013; 14(1): 939-10.
25. Liiping Qiao, Chenhui, DeneysR,Van der Westhuyen and Jianhua Shao. Adiponectin reduces plasma triglyceride by increasing VLDL triglyceride catabolism. Diabetes.2008; 57(1):1824-9.

26. Xiong Z. Ruan. Zac varjhese, Stephen H. Dysregulation of LDL receptor under the influence of inflammatory cytokines: A new pathway of foam cell formation. World Journal of Diabetes 2001; 60 (5):1716-9.

27. Antonio M. Gotton. Cholesterol, inflammation and atherosclerotic cardiovascular disease: Is it all LDL?Trans Am Clin Climatol Assoc.2011(1) :256-13.

28. Devaraj S, Jialal I. Low density lipoprotein postsecretory modification, monocyte function and circulating adhesion molecules in type 2 diabetic patient with and without macrovascular complication. Circ. 2000; 102:191-6.

29. Essenberg S. High density lipoprotein metabolism. J lipid RES. 1984; 25:1020-24.

30. Tianxin Sheng, Kanginan Yang. Adiponectin and its association with insulin resistance and type 2 diabetes mellitus. Journal of genetics and genomics.2008; 35(6): 321-5.

31. Johannes Hulthe, Bjorn Fagerberg. Circulating oxidized LDL Is associated with subclinical atherosclerosis development and inflammatory cytokines.Arterioscler Thromb Vasc Biol.2002; 22: 1162-5. 